\title{
A Qualitative Analysis of Shell Nouns Used by University Students from China and Sweden
}

\author{
Yishan Gao and Yi Zhang
}

\begin{abstract}
Based on language transfer theory, this study tries to explain the differences in shell nouns used by Chinese and Swedish university students from the perspective of linguistics and culture. From the aspect of linguistic features of Chinese and Swedish, we find that methods of texture, popularity of nouns and sentence patterns lead to the differences in shell nouns. As for cultural differences, the two contrary thinking patterns can explain why Chinese and Swedish tend to use shells in distinct manners. We hope that the results of this study could provide useful insights for the teaching and learning of shell nouns.
\end{abstract}

Index Terms-Cultural differences, language transfer, shell nouns, thinking patterns.

\section{INTRODUCTION}

Shell noun, also named as general noun [1], anaphoric noun [2] and carrier noun [3], draws the attention of many researchers in recent years. However, no matter what the names are, these nouns (such as fact, problem, type, method and issue) have one characteristic in common: they both have a fixed meaning and a changeable meaning. And the changeable meaning of a shell noun needs to be referred from the context it appears in [3]. From previous studies, it can be found that there are few papers comparing shell nouns used by English as a second or foreign language learners from two or more different countries. For this reason, we have employed a corpus-based method to compare the frequency, lexico-grammatical patterns and cohesive functions of five shell nouns (fact, problem, reason, effect and result) used in the argumentations of Chinese and Swedish university students [4]. Another important reason of choosing these two nations is because we have established an exchanging program with Karlstad University for eight years, so it is possible for us to get the Swedish corpus and other data. Our previous research findings are:

1) In terms of frequency, there is a significant difference between Chinese students and Swedish students. Compared with Swedish students, Chinese students use less shell nouns.

2) Students from the two countries are different in choosing a shell noun pattern in two aspects. First, the lexico-grammatical patterns used by Chinese are not as diverse as Swedish students. Second, whereas

Manuscript received June 14, 2017; revised September 10, 2017.

Yishan Gao and Yi Zhang are with the School of Foreign Languages, Northwestern Polytechnical University, Xi’an, China (e-mail: 460931675@ qq.com, yizhang@nwpu.edu.cn).
Chinese students use the pattern the $+N$ and this/that $+N$ mostly, Swedish students prefer the pattern the $+N+$ that.

3) As for cohesive functions, there is a significant difference in the use of cataphoric reference. When using shell nouns, Swedish students are more likely to establish this kind of cohesion.

From previous results, one question needs to be considered: why there exist so many differences in the use of shell nouns between these two groups of students, as they are all English learners? Based on these differences, we try to make explanations in this paper. It is hoped that through the comparison of shell nouns used by Chinese and Swedish university students, we could have some primary ideas of what factors can influence the development of a second or foreign language. By knowing and using these factors, language teachers and learners from China and Sweden, or even from eastern and western countries, could have a better understanding of shell nouns.

\section{LITERATURE REVIEW}

\section{A. Language Transfer}

Since English as a second or foreign language learners have developed certain linguistic habits when acquiring their first language, new linguistic habits will be influenced by the former ones when people try to learn a second language [5]. The language transfer theory believes that the acquisition of new knowledge is based on previous knowledge and the completion of a former task will of course influence the next learning task. There are three types of language transfer and the classification of them depends on the similarity and difference in the form, meaning and usage of the two languages learners face. The first type is positive transfer. It will appear when the two learning tasks in two languages are the same, which will promote the formation of a new linguistic habit during second language learning. Another type is negative transfer, which can usually be found when the two learning tasks in two languages have both similarities and differences. On this occasion, foreign languages learners tend to replace the expressions and ways of understanding with that of their mother tongue, which will lead to harmful transfer in second language learning. The third type is zero transfer, which will appear when there is no connection between the two learning tasks in two languages.

\section{B. Language Family}

It can be summarized from previous literatures that there are mainly three methods to classify languages all over the world: typological classification, areal classification, and 
genetic classification [6]. Among these three methods, the last one is the most popular method in recent years. According to genetic classification, the three languages involved in this paper-Chinese, Swedish and English, belong to two of the biggest language families in the world: Sino-Tibetan languages and Indo-European languages. Chinese belongs to the Chinese group of Sino-Tibetan languages. Swedish belongs to the Northern brunch of Germanic group in Indo-European languages and English belongs to the Western brunch of the same group.

\section{Differences between Chinese and Swedish}

Language learners gradually realize that in order to master a second or foreign language, they need to understand the characteristics of that language. And the most efficient method is to compare that language with their mother tongue [7]. When learners are faced with complicated linguistic phenomenon of a foreign language, their mother tongue may improve the proficiency of that language. But it is also possible that their first language may interfere with the acquisition of a second language. Since Chinese and Swedish belong to two different language families, the two languages should have developed their own linguistic features. So it is inevitable that university students from China and Sweden bring the linguistic features of their mother tongues into the acquisition process of English, which will of course make their interlanguages contain the features of their mother tongues. In this paper, interlanguage means "the separateness of a second language learner's system, a system that has a structurally intermediate status between the native and target languages [8].”

\section{Differences between Eastern and Western Thinking Patterns}

The way of thinking has a close relationship with language. It is the deep mechanism of language's generation and development [7]. At the same time, it is language that makes thinking form and grow. Actually, most of the time, the way of thinking is expressed in certain language forms. And different thinking patterns are one of the most important reasons that make languages different from each other. The use of language reflects the choice and creation of thinking. In simple terms, that is, what the thinking pattern is, what the language will be. When language learners are from different countries, due to the differences in thinking patterns, they have a high possibility to acquire different interlanguages.

\section{Methodology}

Specifically, this study addressed the following two research questions:

(1) What are the possible reasons for the differences of shell nouns used by Chinese and Swedish students from the perspective of linguistics?

(2) What are the possible reasons for the differences of shell nouns used by Chinese and Swedish students from the perspective of culture?

A model was established to illustrate the research procedure. And in order to show how several theories are combined together for analyzing the differences in a more direct way, this model was drawn into a flow chart (Fig. 1).
From the above figure it can be seen that first of all, because Chinese and Swedish belong two different language families, there are large differences in linguistic features between them. Also, due to the geographical locations of the two countries - on in the eastern of the world and the other in the northern Europe, people from China and Sweden have formed different thinking patterns. Finally, the differences in linguistics and thinking patterns combine with each other and are transferred into language learning, which lead to two distinct interlanguages. And this is the reason why there are so many differences in shell nouns used by Chinese and Swedish university students, although they are all English learners.

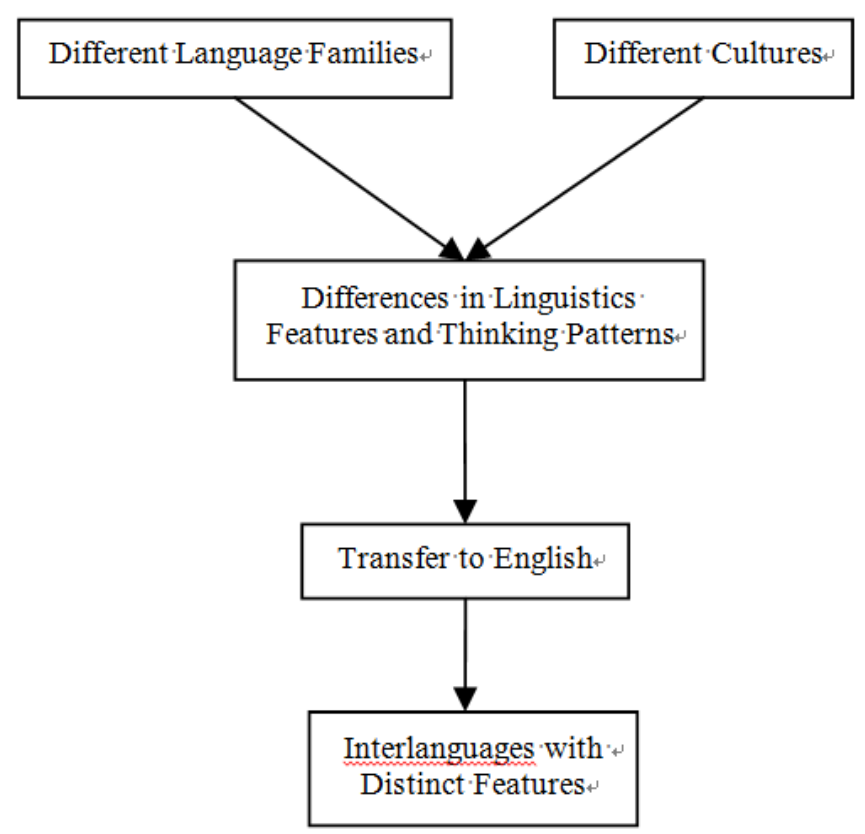

Fig. 1. The qualitative analysis model of differences in shell nouns.

Our previous research [4] used two corpora, made up of compositions of English majors from China and Sweden. The Chinese corpus is a part of the Written English Corpus of Chinese Learners (WECCL). WECCL is made up of 4,950 essays, including argumentations and expositions from English majors and non-English majors. The total number of tokens is 1,248,476 and the major part of this corpus is argumentations written by English majors. The Swedish corpus is a part of the Uppsala Student English Corpus (USE). USE is made up of 1,489 compositions from English majors, mainly freshmen, including argumentations, narration and short papers. The total number of tokens is 1, 221,265.

\section{RESUlTS AND DisCUSSION}

\section{A. Differences Caused by Linguistic Features}

\section{1) Methods of texture}

One of the important functions of shell nouns is to establish cohesion in a text by certain lexico-grammatical patterns [9]. This kind of cohesion is explicit, which mainly relies on grammar and cohesive markers. However, Chinese language usually centers on semantics, and relies on the content of a text to be cohesive [10].This is what we call 
parataxis. As one of the language in Indo-European languages, Swedish and other Germanic languages mainly use hypotaxis to establish cohesion. Under this circumstance, it makes sense that why as a way of establishing cohesion, shell nouns are used less by Chinese than by Swedish.

In Example (1), two groups of sentences are given. Group (a) offers the Chinese translation of the English sentence "It is no problem that he has gone", the phonetic transcription and meaning of every Chinese characters or phrases. In group (b), the Swedish translation of the same English sentence and the meaning of every Swedish word are provided. From this example it can be found that Swedish has a very similar method of texture with English: they both use hypotaxis to organize a sentence; but Chinese adopts a completely different method and people always rely on meaning to connect several clauses together

Example (1): It is no problem that he has gone.
(a) 他 走了,
这没问题。
Ta zou le,
zhe mei wenti.
He go tense marker, this no problem.

(b) Det är inget problem att han har gått.

It is no problem that he has gone.

\section{2) Popularity of nouns}

When an abstract noun is inserted in a certain lexico-grammatical pattern, this noun can be considered as a shell noun [11]. Because there is no specific category for shell nouns in the grammatical system of English, and it needs specific context to determine whether an abstract noun is a shell noun or not, so we use abstract nouns instead of shell nouns for some of the comparisons in this paper, as shell nouns are included in the category of abstract nouns and have basically the same conception with abstract nouns.

Although abstract nouns exist in both Chinese and Swedish, the numbers of abstract nouns are not the same. In Chinese, abstract nouns are fewer than in languages of Indo-European family. In old Chinese, not many words are real abstract nouns [10]. The phenomenon that more abstract nouns exist in Indo-European languages whereas less in Chinese is transferred into the English learning process, leading to positive transfer for Swedish students and negative transfer for Chinese students. It is the first reason why students from the two countries have differences in using shell nouns.

Second, sentence structures of Indo-European languages are suitable for using abstract nouns. No matter how much content a sentence delivers, one finite verb is usually enough. Phrases and clauses containing non-finite verbs follow the main sentences through grammatical relationship [10]. This kind of sentence structure is very suitable for using abstract nouns and phrases containing abstract nouns. On the contrary, the grammar system of Chinese is underdeveloped. Thus Chinese sentences are mostly formed by chronological order or logical order, which center on verbs. Noun phrases do not conform to the Chinese habits of expression.

Example (2) is used to illustrate this point. In the Chinese translation, five finite verbs are employed and they all belong to the same level. But in the original English sentence, one finite verb and four non-finite verbs are used, so these verbs actually belong to two levels. Except for the order of some words and the miss of definite article, the sentence structure of Swedish is nearly the same with that of English, and this kind of structure is suitable for using nouns.

Example (2): To promote economic growth and maintain social stability, we must take the opportunity to deepen the reform and open China wider to the outside world.

(a) 我们必须 抓住 机遇, 深化 改革, Women bixu zhuazhu jiyu, shenhua gaige, We must take opportunity, deepen reform, 扩大 开放, 促进 发展, 保持 kuoda kaifang, cujin fazhan, baochi expand openness, promote development, maintain 稳定。 wending. stability.

(b) För att främja ekonomisk tillväxt och bevara To promote economic growth and maintain social stabilitet, måste vi ta tillfälle och social stability, must we take opportunity and fördjupa reformen och öppna Kina mer för deepen reform and open China wider to världen utanför. world outside.

(Adapted from Example 7(a) and 7(b) in [10], pp. 260, 263)

What's more, negative sentences in Chinese are usually achieved by not that is attached to verbs. It will become improper if a negative sentence is developed by abstract nouns. Last but not least, Indo-European languages have a highly developed system of prepositions, which create conditions for the use of abstract noun structure. In Chinese, the number of prepositions is comparatively smaller, so the use of abstract noun structure is limited by grammar [10]. Students transfer the diversity or lack of abstract noun structure in their mother tongues into English learning, which can explain why they use shell nouns and shell noun patterns with different frequencies.

\section{3) Run-on pattern and hierarchical structure}

Run-on pattern is very typical sentence pattern in Chinese. The formation of such a sentence pattern is similar to stream of consciousness: one clause followed by another and can be endless. Influenced by this linguistic feature, English sentences created by Chinese students usually have this run-on pattern. They connect several short simple sentences together by and or comma, which can be considered as a linear structure [10]. On the contrary, the sentence structure in Indo-European languages is hierarchical. The center of this hierarchical structure is subject and finite verb, which usually make the main clause, and relatives, prepositions, connectives, and participles are used to embed phrases and clauses to the main clause. This can in one way explain why Chinese and Swedish students prefer two types of shell noun patterns.

Example (3): As a teacher richly endowed with a generous heart and a noble mind, he was widely admired by his students for his genuine devotion to education.

(a) 他是一个老师，胸怀 宽广，思想 Ta shi yige laoshi, xionghuai kuanguang, sixiang He be a teacher, heart generous, mind 


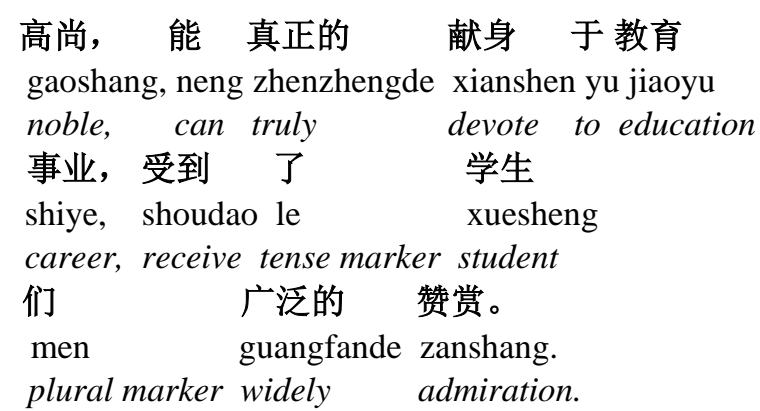

(b) Som lärare rikt begåvad med ett generöst hjärta As teacher richly gifted with one generous heart och ett ädelt sinne, beundrades han mycket av and one noble mind, was admired he much by sina studenter för sin genuina hängivenhet för his students for his genuine devotion for undervisning.

education.

(Adapted from Example (4) in [10], pp. 252, 253)

Example (3) distinguishes the run-on pattern and hierarchical structure. In the Chinese translation, the small clauses have no grammatical connections with each other and are connected by a same sentence topic. Each small clause is very short and the author of this sentence can continue it without considering too much about the structure. The original English sentence and the Swedish translation both have a hierarchical structure, which means each of the small clauses is connected closely with another and embeded to the main clause.

The shell noun patterns the $+N$ and this/that $+N$ are mostly used by Chinese student. They are a very typical minor sentence pattern, by which run-on sentences and linear sentences are usually produced. However, Swedish students prefer the pattern the $+N+$ that the most, by which long and complicated hierarchical sentences are usually made.

\section{B. Differences Caused by Thinking Patterns}

\section{1) Concrete thinking and abstract thinking}

Chinese are used to concrete thinking whereas Swedish are used to abstract thinking, and nouns often lead to the abstraction of language expression. Reasons why concrete thinking is more favorable in eastern nations whereas abstract expressions are popular in western nations are summarized [7]. First, the philosophical background of Chinese language is the comprehension of Confucianism, Taoism, and Buddhism. This comprehension needs to be specific, so Chinese people are good at concrete thinking. On the contrary, western people are good at abstract thinking and theoretical research on it since ancient times, so they are experts in using abstract expressions, like shell nouns. Second, Chinese is an imagery language, the written symbols of which have the characteristics of pictographic, meaningful, and phonographic. Compared with Chinese, the written system of Swedish is single, which is mainly phonographic, so Swedish have a more abstract language system. Third, Indo-European languages have a rich system of affix. A word can be easily changed into another with different part of speech. That is, prefix and suffix provide convenience for abstract expressions. However, in Chinese, affix is not so many, so it is not easy to change concrete word into an abstract one. Because of the concrete thinking mode of Chinese people, shell nouns are usually neglected.

\section{2) Hindsight and foresight}

In general, people in China like to look back, which makes their thinking pattern conservative with hindsight. In contrast, western people prefer looking forward and their thinking pattern is usually creative with foresight [7]. This difference can explain why students from China and Sweden are different in choosing shell noun patterns and type of reference. Shell noun patterns the $+N$ and this/that $+N$ are used most frequently by Chinese students, and they both belong to anaphoric reference [12], which means readers have to look back on the previous text for what a shell noun really represents. This is a kind of review, or hindsight. As for Swedish students, they use the $+N+$ that mostly. This pattern belongs to cataphoric reference [12], which requires readers find a referent in further text which is going to be introduced. This is what we call foresight.

\section{3) Induction and deduction}

Some scholars believe that Chinese people are good at summarization: they can conclude a book into a word; on the contrary, western people are able to enrich a sentence into a book. This is actually the difference between induction and deduction. The pattern the $+N$ and this/that $+N$ are usually used to summarize previous text and draw a conclusion whereas the $+N+$ that is often employed to make deduction and important information usually appear in the following text.

\section{CONCLUSION}

From linguistics and culture, this study offers some possible explanations for why Chinese university students and Swedish university students have differences in using shell nouns. The results have shown that first language plays an important role in second or foreign language learning. No matter consciously or unconsciously, learners tend to transfer the linguistic features of their first language into a second or foreign language, which can make their interlanguage share many similar features with their first language. At the same time, the interlanguage can also be strongly influenced by learners' way of thinking. As Chinese and Swedish have different thinking patterns, they are influenced by their own way of thinking when using shell nouns, as well as other language phenomena.

For theoretical purpose, the research results can enrich theories in second language acquisition and comparative linguistics; for practical purpose, the results can also provide English learners and teachers with reference in learning and teaching shell nouns. One limitation of this study is that the language proficiency of English learners from China and Sweden is only controlled by their grade and major. Other measurements, like an English proficiency test, can not be given to the students. However, this is a common problem of using already established corpora from different countries. In future studies, research articles of high quality can be used as subjects to discover whether there exist differences in high-proficiency English users from different countries or not. 


\section{ACKNOWLEDGMENT}

We would like to express our sincere thanks to Professor Solveig Granath from Karlstad University for her translations of the Swedish examples in our study and the valuable suggestions on this paper.

This work was supported by the Seed Foundation of Innovation and Creation for Graduate Students in Northwestern Polytechnical University (No. Z2017062).

\section{REFERENCES}

[1] M. A. K. Halliday and R. Hasan, Cohesion in English, London: Longman, 1976.

[2] G. Francis, Anaphoric Nouns, Birmingham: University of Birmingham, 1986.

[3] R. Ivanic, "Nouns in search of a context: A study of nouns with both open-and closed-system characteristics," International Review of Applied Linguistics, vol. 29, no. 2, pp. 93-114, May 1991.

[4] Y.S. Gao and Y. Zhang, "A comparison of shell nouns used by Chinese and Swedish,” in Proc. 14th Asia TEFL Conference, pp. 199-205, 2016.

[5] Y. L. Xu, Contrastive Linguistics, Shanghai: Shanghai Foreign Language Education Press, 2002.

[6] C. Z. Huang, "Classification of the world's languages," Foreign Language Teaching and Research, vol. 19, no. 1, pp. 1-11, Jan. 1987.

[7] S. N. Lian, Contrastive Studies of English and Chinese, Beijing: Higher Education Press, 2010.

[8] L. Selinker, “Interlanguage,” International Review of Applied Linguistics in Language Teaching, vol. 10, no. 3, pp. 209-232, Aug. 1972.

[9] R. N. Aktas and V. Cortes, "Shell nouns as cohesive devices in published and ESL student writing,” Journal of English for Academic Purposes, vol. 7, no. 1, pp. 3-14, Jan. 2008.

[10] J. G. Cai, A Contrastive Study of Writing \& Rhetoric in English and Chinese, Shanghai: Fudan University Press, 2006.

[11] H. Schmid, English Abstract Nouns as Conceptual Shells: From Corpus to Cognition, Berlin: Walter de Gruyter, 2000.
[12] M. A. K. Halliday, An Introduction to Functional Grammar, Beijing: Foreign Language Teaching and Research Press, 2008.

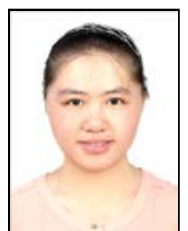

Yishan Gao was born in Kaifeng, Henan, China on May 22, 1993. She is a graduate student of the School of Foreign Languages, Northwestern Polytechnical University (NPU), Xi'an, China, majoring in foreign linguistics and applied linguistics. She obtained her bachelor degree of arts in NPU in 2015.

She has published several papers both in Chinese and in English. Her paper titled "A study of psycholinguistic empirical studies in second language acquisition: Research methods and methods of data collection" was published in International Journal of Arts and Commerce in 2016. Another paper titled "Research on pronoun it in English discourse for science and technology" was published in College English in 2015. She has also been invited to attend the 13th and 14th Asia TEFL conferences. Her current research interests are English for academic purposes and second language acquisition.

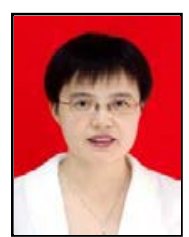

Yi Zhang was born in Baojing, Hunan, China on September 29, 1967. She is a professor at the School of Foreign Languages, Northwestern Polytechnical University (NPU), Xi'an, China. She obtained her master degree of arts in NPU in 2006; bachelor degree of arts in Shaanxi Normal University, Xi'an, China in 1989.

She presently works as the vice dean and graduate supervisor at School of Foreign Languages, NPU. She has presided over or participated in more than 20 research projects, and published over 40 academic papers. Some of her publications include: “A review of studies on discourse markers in China” in Journal of Shenzhen University (humanities \& Social Sciences), 2010; "Comparative studies of NESTs' and NNESTs, Classroom Feedback” in Journal of Zhengzhou University, 2010; “A comparative study of NESTs and NNESTs classroom interaction in Chinese context” in Teaching English in China, 2009. Her current research interests include the education and development of teachers and comparative researches on language education.

Prof. Zhang is a member of Asian Teachers' Association, oral examiner of Business English Certificate (BEC) test and reviewer of Linguistics and Literature Studies. She has been awarded for her teaching and researching at national and provincial levels for seven times. 